Care: Jurnal Ilmiah Ilmu Kesehatan Vol .8, No.1, 2020, hal 30-38

Tersedia online di https://jurnal.unitri.ac.id/index.php/care

ISSN 2527-8487 (online)

ISSN 2089-4503 (cetak)

\title{
GEJALA DEPRESI PADA REMAJA DI SEKOLAH MENENGAH ATAS
}

\author{
Desi $^{1)}$, Aris Felita ${ }^{2)}$, Angkit Kinasih ${ }^{3)}$ \\ ${ }^{1), 2)}$ Program Studi Ilmu Keperawatan, UKSW-Salatiga \\ ${ }^{3}$ Program Studi Pendidikan jasmani Kesehatan dan Rekreasi, UKSW Sslatiga \\ Email: desi.desi@uksw.edu
}

\begin{abstract}
Depression is a mental disorder that is common in the world. Depression can cause difficulty concentrating, affecting once social functioning, and adjusting difficulty, and can even lead to suicidal behavior for individuals who bave severe depression. Adolescence is a period of development, and during this period, adolescents often experience a period of identity and ambiguous crisis. This crisis identity causes adolescents to become unstable, aggressive, the conflict between attitudes and behavior, emotional and sensitive shakiness, too fast, and rash to take extreme actions. The purpose of this study was to identify depressive symptoms in adolescents in high school. Quantitative research with this survey approach involves students from SMA NEGRI 1 SALATIGA who were chosen randomly (random sampling). Determination of sample size using the Slovin formula with an error tolerance of 0.05. A total of 175 participants consisted of grades 10 and 11, consisting of 75 male students and 100 female students. The results of the study showed that $24 \%$ of male students were identified with symptoms of depression while females, there were as many as 40\% identified as depressive symptoms. The limitation of this study is that it only uses one variable, showing the percentage of depressive symptoms in early adolescents.
\end{abstract}

Keywords: Adolescence; depression symptoms.

\begin{abstract}
ABSTRAK
Depresi merupakan salah satu penyakit gangguan mental kronis yang dapat menyebabkan "kelumpuhan" bagi penderitanya bahkan dapat berujung pada perilaku bunuh diri. Pada perkembangannya, depresi sudah tidak lagi mengenal usia maupun status sosial penderitanya. Oleh karenanya, deteksi dini gejala depresi sangat penting dilakukan, terutama pada masa kanak-kanak yan mana perilaku perundungan paling sering terjadi antar sesame siswa. Selanjutnya, aktivitas untuk menurunkan gejala-gejala depresi pun perlu untuk dirancang dan diupayakan pelaksanaannya sehingga gejala yang muncul dapat terkendali. Penelitian bertujuan untuk mengidentifikasi gejala depresi pada remaja di Sekolah Menengah Atas. Penelitian kuantitatif dengan pendekatan survei ini melibatkan partisipan siswa-siswa dari SMA NEGRI 1 SALATIGA yang dipilih secara acak (random sampling). Penentuan besaran sampel menggunakan rumus Slovin dengan toleransi error 0.05. Total partisipan berjumlah 175 yang beranggotakan kelas 10 dan 11 terdiri dari 75 siswa laki-laki
\end{abstract}

Cara mengutip: Desi., Felita, Aris \& Kinasih, Angkit. (2020). Gejala Depresi pada Remaja di Sekolah Menengah Atas. Care:Jurnal Ilmiah Ilmu Kesehatan, 8(1), 30-38

Retrieved from https://jurnal.unitri.ac.id/index.php/care/article/view/1144 
dan 100 siswi perempuan. Hasil dari penelitian menunjukkan bahwa 24\% siswa laki-laki teridentifikasi gejala depresi sedangkan perempuan, ada sebanyak $40 \%$ yang teridentifikasi gejala depresi. Keterbatasan penelitian ini ialah hanya menggunakan satu variabel, menunjukkan persentase gejala depresi pada remaja awal.

Kata Kunci: Gejala depresi; Remaja SMA.

\section{PENDAHULUAN}

Remaja, atau yang dikenal dengan istilah adolescere dalam Bahasa latin berarti to grow atau to grow maturity (Jahja, 2011). Badan Kesehatan Dunia World Health Organization (WHO, 2015) memberikan batasan mengenai siapa remaja secara konseptual. Dikemukakan oleh WHO, remaja ditandai dari tiga aspek yaitu biologis (meliputi pertumbuhan organ reproduksi sekunder hingga masa pubertas), psikologis (cara berpikir dan pengelolaan emosian dari anak-anak menuju dewasa), dan yang selanjutnya ialah sosial ekonomi, remaja cenderung lebih mandiri dari anak-anak yang karakteristiknya bergantung total.

Dalam teorinya, Erikson (1998) menjelaskan bahwa masa remaja berfokus pada pembentukan jati diri, yang mana individu menyadari benar bahwa dirinya adalah manusia yang unik, yang memiliki autonomi untuk menentukan apa yang akan dialakukannya. Pada fase ini, individu mulai mempelajari dirinya lebih dekat seperti sifat yang dimiliki, siapa dirinya, apa tujuannya untuk masa yang akan dating, kekuatan dan kelemahan diri serta cara mengontrol keinginan/hasrat yang dimiliki.

Lanjut Erikson (1998) bahwa remaja dibedakan menjadi tiga tahapan yaitu masa remaja awal, masa remaja pertengahan, dan masa remaja akhir. Perempuan remaja awal ditentukan dari rentang usia yaitu 13-15 tahun dan 15-17 tahun pada laki-laki. Untuk remaja perempuan pertengahan yaitu 15-18 tahun dan pada laki-laki yaitu 17-19 tahun. Terakhir adalah kriteria masa remaja akhir pada perempuan ada pada rentang 18-21 tahun dan pada laki-laki 19-21 tahun. Masa remaja awal merupakan masa transisi anak sekolah menuju individu dewasa dini. Perkembangan emosi remaja pada tahap memasuki remaja awal akan menunjukan emosi yang sensitif, labil, dan temperamental seperti contoh di tahap ini remaja cenderung akan mudah tersinggung, seding, murung dan bahkan marah. Remaja yang berkembang di lingkungan yang kurang kondusif, 
kematangan emosionalitasnya terhambat sehingga akan mengakibatkan tingkah laku negatif misalnya agresif, lari dari kenyataan (Faturochman, 2006).

Tugas perkembangan remaja ditujukan untuk mengontrol sikap dan perilaku kekanak-kanakan menjadi sikap yang lebih tenang, pengertian dan penuh pengendalian diri. Sikap-sikap yang dimaksud contohnya ialah penerimaan dirinya sendiri secara menyeluruh. Penerimaan diri sangat penting agar remaja dapat menempatkan diri dengan baik dan bijak saat berada di lingkungan masyarakat (Papalia \& Olds, 2001).

Selain dari pada itu, masa remaja seringkali dikaitkan dengan stereotip negatif seperti perilaku menyimpang. Faktanya, banyak teori-teori tentang tumbuh kembang manusia, menjelaskan bahwa masa transisi yang dari anak-anak menuju dewasa, membuat rembaja memiliki sifat keingintahuan dan cobacoba terhadap banyak hal. Ditambah lagi dengan sikap dan ego yang tinggi membuat remaja mudah mendapat hasutan dan melakukan hal-hal yang menurut nilai-nilai sosial adalah suatu penyimpangan. Dampaknya, tidak sedikit remaja yang mengalami kondisi emosi yang labil, kerentanan stress hingga depresi (Papalia \& Olds,2008).

Depresi adalah bagian dari penyakit mental yang sangat serius di dunia. Dampak negatif yang muncul akibat depresi seperti sulit berkonsentrasi, terbatasanya interaksi sosial, tergangunya penyesuaian diri bahkan munculnya resiko bunuh diri, membuat masalah ini perlu penanganan serius (Nevid, \& taylor, et al. 2006). Data melaporkan bahwa sejumlah 800,000 kasus bunuh diri merupakan dampak dari depresi (WHO, 2015). Tidak hanya itu, Depresi Mayor dinobatkan sebagai kasus tertinggi dalam domain penyakit mental di dunia dan terus meningkat setiap tahunnya dalam 10 tahun terakhir (Richards, 2011). Sementara di Indonesia, individu dengan penyakit depresi ada pada kisaran $6 \%$ dari total populasi (Riskesdas, 2013). Temuan lain oleh Badan pusat statistik (2014) bahwa setidaknya ada sekitar 3,4 juta remaja usia 10-19 mengalami gangguan mental di tahun 2013 dan depresi sebagai gangguan yang paling umum terjadi (Badan Pusat Statistik, 2014).

Hasil penelitian terkait depresi pada remaja SMA di Malang, Jawa Timur, menunjukkan hasil bahwa remaja 
mengalami depresi ringan sebanyak $32,5 \%, 28,2 \%$ remaja dengan depresi moderat, dan remaja dengan depresi berat sebanyak 11,1\% (Asmika, \& Handayani, et al. 2008). Hingga kini, belum ada data penelitian yang realiabel mengenai jumlah remaja yang mengalami depresi, baik yang sudah di berikan penanganan maupun yang belum, berdasarkan pada penelitian tersebut, penting dilakukan penelitian mengenai depresi pada remaja di Indonesia. Penelitian ini dilakukan untuk menggambarkan kondisi remaja tingkat SMA di salah satu sekolah di Salatiga. Tujuannya ialah mendapatkan data terkait persentasi gejala depresi yang dialami siswa SMA laki-laki dan perempuan. SMA yang terpilih merupakan salah satu SMA favorit dan unggulan di Salatiga dengan tingkat persaingan akademik yang tinggi antar siswa.

\section{METODE PENELITIAN}

Penelitian ini menggunakan metode deskriptif kuantitatif, pengambilan data menggunakan survei dengan kuesioner Glasgow Depression Scale. Penentuan Partisipan penelitian ini ditentukan menggunakan dua kelompok yang dipilih secara random di SMA NEGRI 1 SALATIGA. Partisipan yang ikut dalam penelitian ini meliputi siswa kelas $\mathrm{X}$ dan XI yang mengikuti ekstrakurikuler
Pramuka. Total populasi siswa kelas 10 dan 11 sejumlah 243 siswa. Dengan menggunakan rumus Slovin, besaran sampel minimal adalah 152, akan tetapi, atas pertimbangan kemungkinan error, total partisipan yang terlibat sejumlah 175 siswa

Gejala depresi diukur menggunakan kuesioner yaitu Glasgow Depression Scale yang diadaptasi dari Midham,J,.Espie,C.A tahun 2003. Kuesioner tersebut telah di adaptasi kedalam bahasa Indonesia, sebelum digunakan kuisioner di uji validitas dan realibitasnya, dari hasil uji tersebut di peroleh koefisien reliabilitas Alpha: 0.757 dengan validitas pernyataan (korelasi total pernyataan) yang berkisar antara 0.280-0.636.

Glasgow Depression Scale merupakan kuesioner yang digunakan untuk mengukur gejala depresi yang di rasakan partisipan dalam 2 minggu terakhir. Penelitian ini menggunakan metode kuantitatif deskriptif. Kuesioner ini terdiri dari 20 penyataan masing-masing 5 pernyataan positif dan 15 pernyataan negatif rentang skor tiap pernyataan ialah 0 untuk pilihan tidak pernah sampai 2 untuk pilihan sering dan untuk pernyataan negatif skor di hitung terbalik, responden dinyatakan teridentifikasi 
gejala depresi jika memiliki skor akhir lebih dari 13. Penyajian data menggunakan Tabel Distribusi Frekuensi dan Persentase. Pengambilan data ini dilakukan pada rentang tanggal 6-15 Mei 2018 oleh tim peneliti.

\section{HASIL}

Hasil dari gejala depresi pada anak remaja awal, di paparkan dalam bentuk tabel dan grafik yang dapat menunjukkan hasil dari partisipan. Berikut ini adalah profil partisipan, hasil dari kuesioner.

Tabel 1. Distribusi jumlah responden berdasarkan jenis kelamin.

\begin{tabular}{ccccc}
\hline Responden & Kelas & $\mathbf{f}$ & $\mathbf{\%}$ & $\begin{array}{c}\text { Total } \\
\mathbf{\%}\end{array}$ \\
\hline Laki- laki & 10 & 42 & 24,57 & $\mathbf{4 3 , 4 3}$ \\
& 11 & 33 & 18,86 & \\
Perempuan & 10 & 68 & 38,28 & $\mathbf{5 6 , 5 7}$ \\
& 11 & 32 & 18,29 & \\
$\mathbf{n}$ & & 175 & $100 \%$ & $\mathbf{1 0 0}$ \\
\hline
\end{tabular}

Berdasarkan Tabel 1 dapat dilihat bahwa dari keseluruhan responden, siswa perempuan lebih banyak (56,57\%) dalam hal jumlah ketimbang siswa laki-laki.

Tabel 2. Hasil Pengukuran Gejala Depresi

\begin{tabular}{lcc}
\hline \multicolumn{1}{c}{ Responden } & \multicolumn{2}{c}{$\mathbf{f ( \% )}$} \\
\cline { 2 - 3 } & Depresi & $\begin{array}{l}\text { Tidak } \\
\text { Depresi }\end{array}$ \\
Laki-Laki & $18(10,3 \%)$ & $57(32,6 \%)$ \\
Perempuan & $40(22,9 \%)$ & $60(34,3)$ \\
Total (n=175) & $\mathbf{5 8 ( 3 3 , 1 \% )}$ & $\mathbf{1 1 7 ( 6 6 , 9 \% )}$ \\
\hline
\end{tabular}

Tabel 2 menunjukan bahwa gejala depresi banyak dialami oleh siswa perempuan yaitu sebanyak 22,9\%, yang jika dipresentasikan bedasar jumlah partisipan perempuan (100 partisipan), maka sejumlah 40\% mengalami gejala depresi. Sementara itu, meskipun responden yang mengalami depresi sejumlah 33,1\% dari total keseluruhan responden, namun angka ini cukup tinggi mengingat depresi merupakan salah satu yang penyakit yang paling banyak menyebabkan seseorang bunuh diri (WHO, 2019).

\section{PEMBAHASAN}

Munculnya gejala depresi yang ditemukan pada partisipan penelitian ini pada dasarnya semakin menguatkan hasil-hasil penelitian sebelumnya. Suatu penelitian yang dilakukan di Amerika tentang gejala depresi menjabarkan bahwa remaja awal usia 11-13 tahun memiliki potensi depresi ringan ketimbang anak remaja usia 14-18 tahun. Permasalahan-permasalahan yang muncul sebagai pemicu terjadinya depresi pada remaja umumnya meliputi kurangnya rasa percaya diri terhadap penampilan fisik. Namun jika ditilik dari segi status sosial, remaja dengan status sosio ekonimi rendah memiliki potensi terkena depresi berat ketimbang mereka yang memiliki status sosial ekonomi tinggi (Pratt dan 
Brody, 2012)

Gejala depresi yang muncul pada remaja meliputi perasaan sedih yang berkepanjangan, mengisolasi diri, lebih banyak melamun saat sedang dalam kelas. Tidak hanya itu, gangguan makan, gangguan pola tidur, sering merasa lelah, lesu atau kurang bertenaga, gangguan interaksi sosial, sulit konsentrasi dan sulit mengambil keputusan menjadi raga gejala depresi yang menyertai. Depresi pun dapat menyerang kepribadian dan sifat seorang remaja yang selanjutnya akan mudah merasa putus asa, tidak ada inisiati, bahkan ketidaktertaikan dalam berbagai hal (Hawari, D., 2005).

Penelitian yang berjudul “ Depresi Pada Remaja” yang ditulis oleh Soetjiningsih (2011), mengatakan bahwa depresi memiliki tiga gejala utama yaitu perasaan yang tertekan (dapat disampaikan secara verbal maupun gestur, warna emosi dan ekspresi wajah), kesulitan berpikir (tampak dari waktu lama yang digunakan untuk merespon, berbicara sedikit ataupun ungakapan langsung penderita terkait kesulitan konsentrasi) dan yang ketiga ialah kelambatan psikomotor (ditunjukan dari fisik yang mudah Lelah, lemas, tidak antusias, ragu-ragu, bahkan mucul gangguan somatic yang tidak menentu).

Dalam teori perkembangan, remaja merupakan fase usia yang rentan dengan mengalami depresi, hal ini terkait dengan tuntutan akademis, sosial maupun tekanan dari keluarga (Dunkley, et al., 2000). Persaingan akademis menjadi sorotan oleh karena keberadaan sekolah-sekolah yang disiplin terhadap pencapaian/nilai akademis semakin banyak, fenomena ini menjadi semakin diperparah dengan persaingan dan ambisi orang tua agar anaknya menjadi siswa yang multitalenta dan selalu unggul. Ambisi ini kemudian ditunjukan dengan upaya untuk membuat anak-anaknya mengikuti beragam aktifitas bimbingan belajar baik di bidang akademik, olahraga maupun kesenian, di luar aktivitas sekolah. Dari sisi permasalahan sosial, tak terbatasnya pergauan remaja di ruang nyata maupun dunia maya, memberikan kesempatan yang luas bagi remaja untuk terjerumus dalam perilaku menyimpang seperti substance abuse (penyalahgunaan alcohol dan obat-obat terlarang), maupuan perilaku kekerasan yang cenderung agresif dan merusak (Ardjana,2010).

Selain hal-hal di atas, persoalan yang sering ditemukan pada remaja adalah konflik dengan teman sebaya, bullying (perundungan), sulitnya berinteraksi dikelas/lingkungan tempat tinggal, kompetisi yang ketat di kelas serta 
kemampuan untuk menguasai materi yang banyak dalam waktu yang singkat (Sarwono, 2006). Hal ini yang membuat remaja sulit mengatasi masalah yang dialami sehingga remaja mengalami gejala depresi. Hal ini juga dikemukakan oleh Aprilia (2013) dalam penelitiannya yang menjelaskan bahwa remaja yang sering mengalami bullying maka semakin berat depresi yang dialami, sebaliknya remaja yang jarang mengalami bullying maka semakin rendah depresi yang dialami. Selain hal-hal di atas, ketatnya persaingan akademik di lingkungan sekolah utamanya sekolah-sekolah unggulan/favorit, cenderung membuat remaja mudah mengalami stress hingga depresi. Hal ini yang dimungkinkan terjadi pada responden, seperti yang ditunjukan pada hasil penelitian ini.

Meskipun demikian, gejala depresi pada remaja belum menjadi perhatian khusus oleh pihak-pihak terkait. Programprogram promotive seperti sosialisasi tentang kesehatan mental masih jarang dijumpai di sekolah-sekolah. Demikian juga dengan program bimbingan konseling yang seharusnya memiliki tindaklanjut sampai pada pendampingan proses pengobatan dan rehabilitasi bagi siapapun remaja yang terindikasi gejala depresi. Tidak ketinggalan, peran serta dari Orang Tua para remaja serta guru dalam menjaga dan memantau kondisi remaja dengan cara menjadikan anak sebagai rekan bercerita maupun negosiasi yang baik. Orang Tua maupun guru pada kebanyakan kesempatan, memandang tanda-tanda gangguan depresi pada anak remaja adalah sesuatu yang wajar dan tidak perlu penanganan khusus, padahal, diagnosis dan perawatan sejak awal terhadap depresi amatlah penting untuk perkembangan emosi, sosial dan perilaku penderitanya (Haryanto, 2015).

Merujuk pada hasil penelitian ini yang mendapati bahwa perempuan lebih banyak dua kali lipat mengalami gejala depresi dibanding laki-laki, tentunya memiliki penjelasannya tersendiri. Sebuah studi tentang perbedaan jenis kelamin dalam patofisiologi menuju depresi berat pada pasangan kembar lawan jenis oleh Kendler dan Gardner (2014) menjelaskan bahwa perempuan lebih sensitif pada permasalahan hubungan interpersonal, sementara laki-laki lebih pada permasalahan eksternal (contoh pada remaja seperti hobby). Selain itu, terdapat fakta bahwa faktor hormonal punya peranan kuat terhadap perubahan suasana hati (mood). Remaja pada masa pubertas 
tentunya mengalami masa-masa ini utamanya perempuan baik pada tahap pramenstruasi maupun selama menstruasi. Remaja dalam masa pubertas pun lekat dengan penyakit hormonal seperti premenstrual dysphoric disorder atau PMDD (Albert, 2015) Tidak hanya itu, studi pada hewan primata yang dilakukan oleh Shively (2005) pun menerangkan bahwa depresi pada perempuan dipengaruhi oleh fungsi sistem reproduksi seperti hormon esterogen.

\section{KESIMPULAN}

Berdasarkan hasil penelitian dapat disimpulkan bahwa 10,3\% siswa laki-laki dan $22,9 \%$ siswa perempuan mengalami gejala depresi melalui pengukuran dengan Glasgow Depression Scale. Gejala yang ditemukan pada remaja meliputi perasaan sedih yang berlarut-larut, senang menarik diri dari kegiatan sosial/menyendiri, kurang konsentrasi di dalam kelas, kurang nafsu makan atau makan berlebihan, gangguan pola makan, gangguan pola tidur, sering merasa lelah. Keterbatasan penelitian ini ialah hanya menggunakan satu variabel, menunjukkan persentase gejala depresi pada remaja awal. Selain itu, terbatasnya karakteristik partisipan (jenis kelamin dan tingkatan kelas) menjadi salah satu hal yang perlu menjadi sorotan dari penelitian-penelitian selanjutnya, sebab dapat dikatakan pelum terlalu menggali akar masalah gejala depresi yang muncul.

\section{SARAN}

Saran bagi institusi Pendidikan terkait agar bisa melakukan evalusi program-program di sekolah yang sekiranya bisa digunakan untuk pencegahan gejala depresi.

\section{UCAPAN TERIMAKASIH}

Ucapan terima kasih kami sampaikan kepada Tuhan selaku pemberi hikmat, akal budi dan kesehatan, Lembaga UKSW selaku Universitas naungan kami, Institusi Pendidikan SMA Negeri Satu Salatiga, dan yang terkasih, adik-adik siswa dan siswi yang sudah berpartisipasi dalam penelitian ini. Terima ksih juga atas kerjasama yang terjalin antar sesama tim peneliti.

\section{REFERENSI}

Albert P. R. (2015). Why is depression more prevalent in women?. Journal of psychiatry \& neuroscience : JPN, 40(4), 219-221. doi:10.1503/jpn.150205

Ardjana., 2010. Tumbuh Kembang Remaja dan Permasalahnya. Jakarta: Sagung Seto.

Aprilia R, Sofia R. 2013. Depresi Pada Remaja Korban Bullying. Jurnal Psikologi.;9;73-78.

Badan Pusat Statistik. 2014. Data remaja teridentifikasi depresi. Jakarta. Di akses dari www.bps.go.id pada tanggal 30 Oktober 2014.

Balitbang Kemenkes RI. 2013. Riset Kesehatan Dasar; RISKESDAS. Jakarta:Balitbang Kemenkes RI. 
Carr, A. 2001. Abnormal Psychology. Sussex: Psychology Press.

Dunkley, D.M., Blankstein, K.R., Halsall, J., Williams, M.,\& Winkworth, G. 2000. The Relation Between Perfectionism and Distress: Hassles, Coping, and Perceived Social Support as Mediators and Moderators. Journal of Counseling Psychology.47, 437 - 453.

Faturrochman. (2006). Pengantar Psikologi Sosial. Yogyakarta: Pustaka Book Publishing.

Erikson, Erick, H.( 1998). Identitas dan Siklus Hidup Manusia. Bunga Rampai Penerjemah : Agus Cremers. Jakarta : PT. Gramedia.

Handayani, N.,Asmika., Harijanto., 2008. Prevalensi Depresi dan Gambaran stressor Psikososial Pada Remaja Sekolah Menengah Umum di Wilayah Kota Madya Malang.Jurnal Kedokteran Brawijaya. 24:15-21.

Haryanto, Whayuningsih HD, Nandiroh S (2015). Sistem deteksi gangguan depresi pada anak dan remaja. Jurnal Ilmiah Teknik Industri14(2) : 142 152.

Hawari, D., 2005. Manajemen Stres Cemas dan Depresi.Jakarta: Balai Penerbit FKUI.

Jahja, Yudrik, Psikologi Perkembangan, Jakarta: Kencana, 2011

Kendler, K. S., \& Gardner, C. O. (2014). Sex Differences in the Pathways to Major Depression: A Study of Opposite-Sex Twin Pairs. American Journal of Psychiatry, 171(4), 426435. 10.1176/appi.ajp.2013.13101375

Khamim Zarkasih Putro, 2017. Memahami Ciri dan Tugas Perkembangan Masa Remaja. Jurnal Aplikasi Ilmu-ilmu Agama.17(1): 2532.

Nolen-Hoeksema, and S.Desrosiers, A., Klemanski, D. H., (2015). Mapping mindfulness facets onto dimensions of anxiety and depression. Behavior Therapy. doi: 10.1016/j.beth.2013.02.001

Nevid, J. S., Greene, B., Johnson, P. A., \& Taylor, S. (2005). Essentials of abnormal psychology

Papalia, D. E., Old, S. W., Feldman, \& R. D. (2008). Human Development (terjemahan A. K. Anwar). Jakarta: Prenada Media Group.

Pratt, L. A. \& Brody, D. J. Depression in the US Household Population, 2009-2012. NCHS data brief.2014. (172): 1-8.

Richards, D. (2011). Prevalence and clinical course of depression: A review. Clinical Psychology Review, 31, 1117-1125.

Sarwono, S. W. 2006. Psikologi Remaja. Jakarta : Rajagrafindo Persada.

Shively, C. A., Register, T. C., Friedman, D. P., Morgan, T. M., Thompson, J., \& Lanier, T. (2005). Social stressassociated depression in adult female cynomolgus monkeys (Macaca fascicularis). Biological Psychology, 69(1), 67-84. doi: 10.1016/j.biopsycho.2004.11.006

Soetjiningsih. (2011). Tumbuh Kembang Remaja dan Permasalahannya. Jakarta: CV. Sagung Seto.Dharma, K.K. Metodologi penelitian keperawatan: panduan melaksanakan dan menerapkan hasil penelitian. Jakarta: Trans Info Media. Steinberg, Lawrence. 2002. Adolescence. Sixth edition, New York: McGraw HillInc.

World Health Organization. (2015). Fact Sheets:

Depression.http://www.who.int/me diacentre/factsheets/fs369/en/

WHO. (2019, December 4). Depression. Retrieved January 24, 2020, from https://www.who.int/newsroom/fact-sheets/detail/depression 